\title{
Assessment of genetic diversity and wilt disease resistance in hot pepper (Capsicum annuum) germplasm from Ethiopia
}

\author{
Dawit Bedane Woubit ${ }^{1 *}$, Shiferaw Eleni ${ }^{1}$, Sileshi Fitsum ${ }^{1}$, Assefa Mekonnen ${ }^{1}$ \\ \& Aklilu Shimeles ${ }^{2}$
}

\begin{abstract}
${ }^{1}$ Ethiopian Biodiversity Institute, P.O.Box 30726, Addis Ababa, Ethiopia; ORCID: BDW https://orcid.org/0000-0002-6655-9777; SE https:// orcid.org/0000-0001-7748-9834; SF https://orcid.org/0000-0001-7014-5406; AM https://orcid.org/0000-0001-9100-1567

${ }^{2}$ Melkasa Agricultural Research Center, Melkasa, P.O.Box 436, Melkassa, Ethiopia; ORCID: AS https://orcid.org/0000-0002-3952-0201

* corresponding author (e-mail: woubit123@yahoo.com)
\end{abstract}

\begin{abstract}
Hot pepper (Capsicum annuum L. ) is an economically important crop in Ethiopia. Wide variability in hot pepper germplasm in Ethiopia is expected due to the presence of diverse environmental conditions and variation in farming systems. The present study was carried out to evaluate the resistance of 75 hot pepper accessions to wilt disease and assess their genetic diversity using SSR markers. Out of 75 accessions tested, the present study identified 23 accessions that showed resistance (R) with the value of $1-10 \%$ disease incidence. The genetic diversity assessment using 13 polymorphic SSR markers allowed the detection of 111 clear and scorable bands. The number of alleles per locus ranged from 5 to 13, with an average of 8.54. The PIC value ranged from 0.27 to 0.87 with an average of 0.59 . The gene diversity indices were highly variable across SSR loci and ranged from 0.29 to 0.88 with mean genetic diversity of 0.62 . Observed heterozygosity was also highly variable between loci (0.01-0.45) indicating that the accessions were not fixed to homozygosity. Furthermore, genetic diversity parameters were estimated among populations by grouping accessions based on their origin. Within populations, the PIC value ranged from 0.31 to 0.77 . The genetic distances among the eight populations ranged from 0.15 to 0.48 . The observed highest genetic diversity (0.80) in the Amhara region (Gojam) may indicate this area as the primary site for designing in situ conservation for this crop in Ethiopia. The research findings provide baseline information on disease resistance germplasm sources to be used for the breeding program, as well as the status of genetic diversity of the accessions for efficient conservation and proper utilization of the existing genetic resources in the country.
\end{abstract}

Key words: Capsicum annuum, genetic diversity, SSR marker, polymorphism, wilt disease

\section{Introduction}

Hot or red pepper (Capsicum annuum L.) is an important commercial crop cultivated exclusively in tropical and temperate zones of the world and grown on more than 1.5 million hectares worldwide (FAO 2013). C. annuum is the main species of capsicum that is grown in Ethiopia. Ethiopia is among the top five largest hot pepper producer countries in Africa that produces 4511 metric tons of this crop (FAOSTAT 2016). The country is a homeland for many spices including hot pepper (Girma et al. 2008). This crop is widely grown at an altitude ranging from 1400-1900 $\mathrm{m}$ a.s.l. under rainfed and irrigated conditions. Because of its wide use in the Ethiopian diet, hot pepper is an important crop mainly used in traditional foods, valued for its pungency and colour, in the form of 'karia' (green pod) and 'berbere' (dry pod in the form of ground powder). The average daily consumption of hot pepper by Ethiopian adults is about $15 \mathrm{~g}$, which is higher than most other vegetables (EEPA 2014). Ethiopia is one of a few developing countries that have been producing oleoresins for the domestic and export market. Red pepper is widely cultivated in different agro-ecologies of 
Ethiopia. Of the total estimated area under vegetables (238.564.07 ha), the lion share, which is about $73.13 \%$ (174.463.62 ha), was under hot peppers (CSA 2019/20).

Despite tremendous potential use and a wide range of available genetic resources, little effort has been made to improve the quality and productivity of hot pepper in Ethiopia (Shimeles et al. 2018). The average yield of this crop in the country is very low, i.e., $1.8 \mathrm{t} / \mathrm{ha}$ (CSA 2019/20). Among the production constraints, diseases are known to have paramount importance in all hot pepper growing areas of Ethiopia (Korobko et al. 1986; BARC 1999/2000). Among diseases, wilt disease is one of the most economically important diseases and it accounts for yield losses of up to $80 \%$ (Shimeles et al. 2007). The use of resistant varieties is considered the best approach to control the disease (Byoung-Cheorl et al. 2005, Duveiller et al. 2007).

High variability in hot pepper germplasm in Ethiopia is expected due to the presence of diverse environmental conditions and variation in farming systems. Genetic diversity assessment and estimation of relationships among accessions are very helpful for germplasm improvement (Dale \& Schatz 2002). Besides, such information can be used to design effective germplasm conservation and for launching germplasm collection missions, as well as to predict the risk of genetic erosion in a given area. The use of molecular markers is the most suitable method for estimating genetic diversity due to its ability to recognize specific DNA sequences in closely related genotypes, irrespective of growth stage, time, place and agronomy. Among molecular markers, simple sequence repeat (SSR) markers are favoured due to their high polymorphism index (Mun et al. 2006). Therefore, the present study was carried out to evaluate the resistance of 75 hot pepper accession to wilt diseases and assess their genetic diversity using SSR markers. The research findings provide baseline information regarding disease resistance germplasm sources to be used for the breeding program, as well as the status of genetic diversity of the accessions for efficient conservation and proper utilization of the existing genetic resources in Ethiopia.

\section{Material and methods}

\subsection{Plant materials}

A total of 75 hot pepper accessions and a disease susceptible control (reference variety), Mareko fana, were included in this study. The accessions were collected from the regional states of Amhara, Oromia, Southern Nations, Nationalities and Peoples (SNNP) and Benishangul-Gumuz, and obtained from the Ethiopian Biodiversity Institute (EBI) Genebank. The geographic distribution of the tested hot pepper accessions are shown in Table 1 and Fig. 1.

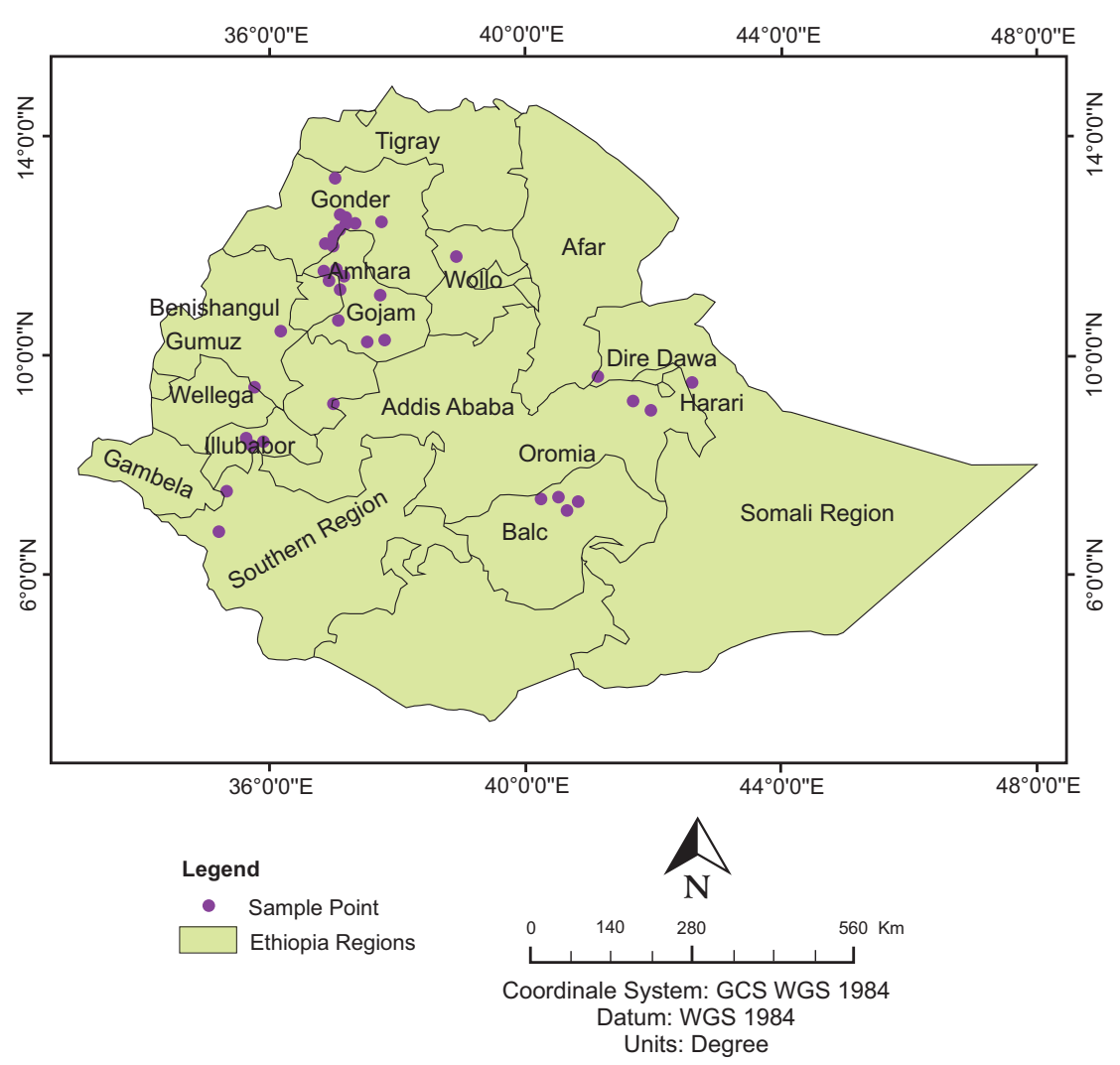

Fig. 1. Map of hot pepper (Capsicum annuum) germplasm collection locations in Ethiopia 
Table 1. Geographic distributions of Ethiopian hot pepper (Capsicum annuum) accessions tested in this study

\begin{tabular}{llcc}
\hline No. & $\begin{array}{c}\text { Regional state and } \\
\text { province }\end{array}$ & $\begin{array}{c}\text { Number of } \\
\text { accessions }\end{array}$ & $\begin{array}{c}\text { Altitude range } \\
\text { (m a.s.l.) }\end{array}$ \\
\hline 1 & Amhara (Gojam) & 24 & $1830-2364$ \\
2 & Amhara (Gonder) & 20 & $1806-1944$ \\
3 & Amhara (Wello) & 2 & $1992-2073$ \\
4 & Oromia (Bale) & 7 & $1775-4954$ \\
5 & Oromia (Illubabor) & 6 & $1464-1877$ \\
6 & Oromia (Wellega) & 1 & 1780 \\
7 & Oromia (Harerge) & 7 & $1200-2100$ \\
8 & SNNP & 2 & $1121-1408$ \\
9 & Benishangul Gumuz & 7 & $1440-1700$ \\
& Total & 75 & \\
\hline
\end{tabular}

2.2. Field screening of hot pepper germplasm against wilt disease

Planting: The tested materials and susceptible control variety were screened in the field under natural infestation at the Melkassa Agricultural Research Center (MARC) in 2019 and 2020, during main cropping and offseason seasons, using lattice design. About seven weeks old seedlings, raised on seedbed, were transplanted to an experimental field with triple rows of $3 \mathrm{~m}$ length and spacing of 70 and $30 \mathrm{~cm}$ between rows and plants, respectively. There were 10 plants per row and, in total, 30 plants per accession. All appropriate agronomic practices, such as: weeding, watering and hoeing, were conducted uniformly both at the nursery and in the experimental field.

Disease scoring: Starting from 30 days after transplanting, the plants were monitored every two weeks for expression of disease symptoms (leaf yellowing and chlorosis, shedding from the base, stunting and total plant wilt and death) to assess the disease occurrence and resistance. Percent disease incidence was used to assess disease resistance according to Galanihe et al. (2004). Disease incidence (DI) percentage was calculated as the proportion of infected plants per plot. Resistance to wilt was determined on the basis of wilt incidence (\%) as: highly resistant (HR): $0 \%$ of wilting; resistant (R): 1-10\%; moderately resistant

Table 2. Amplified primers, their sequences and annealing temperatures used for the analysis of Capsicum annuum

\begin{tabular}{|c|c|c|c|c|c|}
\hline Marker & Repeat & \multicolumn{2}{|c|}{ Primer sequence } & $\mathrm{Ta}^{0} \mathrm{C}$ & $\begin{array}{l}\text { Expected } \\
\text { fragment } \\
\text { size (bp) }\end{array}$ \\
\hline EPM310 & $(\mathrm{CAT}) 13$ & TGGGAAGAGAAATTGTGAAAGC & AGGAAACATGGTTCAATGCC & 53 & $140-172$ \\
\hline EPMS342 & (CTT)7 & CTGGTAGTTGCAAGAGTAGATCG & ATGATCTTTGACGACGAGGG & 55 & $323-343$ \\
\hline EPMS386 & $(\mathrm{CA}) 15$ & ACGCCAAGAAAATCATCTCC & CCATTGCTGAAGAAAATGGG & 50 & $122-170$ \\
\hline EPMS426 & (AT) 15 & GAGGAAACACTCTCTCTCTCTCTCTC & TCAAGAGACCCCAAATAGGG & 55 & $108-118$ \\
\hline GPMS29 & (GT)15GGT7(GTT)2 & CAGGCAATACGGAGCATC & TGTGTTGCTTCTTGGACGAC & 50 & $238-255$ \\
\hline GPMS100 & $\mathrm{T} 5(\mathrm{GT}) 12$ & TCCATACGGTTGGAGGAGAG & ACTATGCTCTGCTGTGCCCT & 53 & $141-169$ \\
\hline GPMS161 & $(\mathrm{AAT}) 25$ & CGAAATCCAATAAACGAGTGAAG & CCTGTGTGAACAAGTTTTCAGG & 53 & $184-259$ \\
\hline GPMS169 & (ATT)5T(TTA)7 & TCGAACAAATGGGTCATGTG & GATGAGGGTCCTGTGCTACC & 53 & $176-220$ \\
\hline GPMS197 & (GA)3(TAT) 16 & GCAGAGAAAATAAAATTCTCGG & CAATGGAAATTTCATCGACG & 52 & $272-344$ \\
\hline HPMS1-5 & (AT) $11(\mathrm{GT}) 17$ & CCAAACGAACCGATGAACACTC & GACAATGTTGAAAAAGGTGGAAGAC & 55 & $269-322$ \\
\hline HPMS2-21 & AT) 11 (AC) 9 (ATAC) 10 & TTTTTCAATTGATGCATGACCGATA & CATGTCATTTTGTCATTGATTTGG & 52 & 286-304 \\
\hline HPMS2-24 & (CT) $17(\mathrm{CA}) 5 \mathrm{~A} 21$ & TCGTATTGGCTTGTGATTTACCG & TTGAATCGAATACCCGCAGGAG & 52 & 205 \\
\hline HPMS1-168 & (TA) $17(\mathrm{GA}) 12$ & GCCCCGATCAATGAATTTCAAC & TGATTTTTGGGTGGAGAGAAAACC & 53 & $172-208$ \\
\hline HPMS1-111 & $(\mathrm{AAT}) 12$ & AAGCTTATCCCTTTCAAATATAA & ATATCTCACGTATTGCGGATTCTT & 50 & 159 \\
\hline HPMS1-214 & (GTTT)2(TTG)9 & TGCGAGTACCGAGTTCTTTCTAG & GGCAGTCCTGGGACAACTCG & 55 & 100 \\
\hline
\end{tabular}

Explanation: 1 - expected fragment size refers to the size reported in different publications 
(MR): 11-20\%; moderately susceptible (MS): 21-30\%; susceptible (S): 31-50\%; highly susceptible (HS): > 50\% (Bayoumi \& El-Bramawy 2007).

\subsection{DNA extraction and SSR genotyping}

Primer selection and optimization: The SSR marker analysis was conducted at the Molecular Laboratory of the Ethiopian Biodiversity Institute, Addis Ababa. Twenty SSR primers, publicly available from Nicolai et al. (2013), were screened on a total of three individuals. Fifteen primers that produced clear and reproducible band patterns were selected for further study using 75 individuals. Primer names, forward and reverse primer sequences, annealing temperature and expected fragment sizes are shown in Table 2 .

DNA extraction: DNA was extracted from one young plantlet (about $0.2-0.3 \mathrm{~g}$ ) randomly selected from three to five individuals of each accession using the modified cetyltrimethylammonium bromide (CTAB) method (Doyle \& Doyle 1987). Two types of buffers - buffer 1 (0.1 M Tris-HCl (pH 7.6), 0.005 M EDTA, $0.35 \mathrm{M}$ sorbitol) and buffer $2(0.2 \mathrm{M}$ Tris- $\mathrm{HCl}(\mathrm{pH} 8.0)$, $0.05 \mathrm{M}$ EDTA, $2 \mathrm{M} \mathrm{NaCl}, 2 \% \mathrm{CTAB}$ ), were mixed in equal amounts and 5\% sodium Laurolysarcosine $(0.8$ final volume) and $0.38 \%$ sodium bisulfate were added just before extraction. After determining the quality and concentration of genomic DNA, DNA samples were diluted to $25 \mathrm{ng} \mathrm{uL}-1$.

PCR amplification and electrophore$\mathrm{s}$ i s: Polymerase chain reactions (PCR) were performed in a PCR express thermocycler (HYBAID), in a final reaction volume of $20 \mu \mathrm{l}$ containing $20 \mathrm{ng}$ genomic DNA, $0.4 \mu \mathrm{M}$ forward primer, $0.4 \mu \mathrm{M}$ reverse primer, $0.2 \mathrm{mM}$ dNTPs, $2 \mu 1$ PCR buffer (10x), $1.5 \mathrm{mM} \mathrm{MgCl}_{2}$, and $1 \mathrm{U}$ Taq DNA polymerase. The following PCR profile was used: initial denaturation step of $3 \mathrm{~min}$ at $94^{\circ} \mathrm{C}$ followed by 35 cycles with denaturation for $30 \mathrm{sec}$ at $94^{\circ} \mathrm{C}$, annealing for $30 \mathrm{sec}$ at $50-60^{\circ} \mathrm{C}$ (depending on the individual primer), and extension for $45 \mathrm{sec}$ at $72^{\circ} \mathrm{C}$. A final extension step at $72^{\circ} \mathrm{C}$ was performed for $7 \mathrm{~min}$ utes. The PCR products were resolved in $2.0 \%$ agarose gel by loading $12 \mu \mathrm{l}$ PCR products and the amplified fragments were stained with ethidium bromide. The gel images were documented using an UVITEC gel doc system and the band sizes were analyzed using UVITEC (UVITEC, Cambridge, UK) software that estimates SSR allele sizes by comparison with a 100 bp DNA ladder (Solis BioDyne, Estonia). In case of weak or no fragment products, PCR amplifications were repeated to exclude failed PCR reactions.

Genetic diversity analysis: The number of alleles, major allele frequencies, gene diversity, heterozygosity, and the polymorphic information content (PIC) were calculated using Power Marker version 3.25 (Liu \& Muse 2005). Clustering of genotypes obtained by the Unweighted Pair Group Method with Arithmetic mean (UPGMA) was performed using DARwin version 6 software (Perrier and Jacquemoud-Collet 2006). The number of effective alleles and analysis of the molecular variation (AMOVA) was performed using GenALEx software version 6.5 (Peakall \& Smouse 2012).

\section{Results}

\subsection{Pepper wilt disease incidence}

The average wilt disease incidence for the hot pepper accessions tested at the Melkasa Agriculture Research Center (MARC) during the 2019 and 2020 cropping seasons is shown in Fig. 2. Of the 75 tested accessions, 23 showed resistance $(\mathrm{R})$ with the value of $1-10 \%$ disease incidence, 20 accessions exhibited moderate resistance (MR) with disease incidence of $11-20 \%$, whereas 21 and 10 accessions were moderately susceptible (MS) and

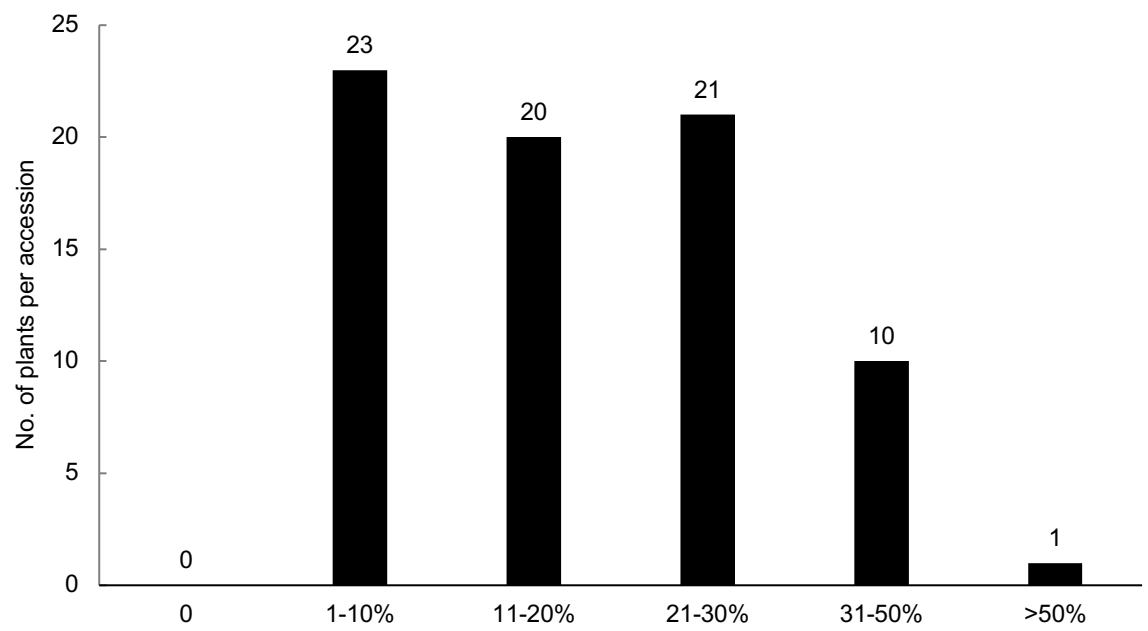

Fig. 2. Disease incidence for the 75 hot pepper (Capsicum annuum) accessions tested in the years 2019-2020 
Table 3. Characteristics of the 13 analyzed microsatellite loci in 75 Ethiopian hot pepper (Capsicum annuum) accessions

\begin{tabular}{llrrrrr}
\hline No. & Marker & $\begin{array}{l}\text { Major Allele } \\
\text { Frequency }\end{array}$ & Allele No. & $\begin{array}{l}\text { Gene } \\
\text { Diversity }\end{array}$ & Heterozygosity & PIC \\
\hline 1 & GPMS169 & 0.28 & 8 & 0.81 & 0.15 & 0.78 \\
2 & GPMS386 & 0.23 & 13 & 0.88 & 0.25 & 0.87 \\
3 & HPMS2-24 & 0.69 & 5 & 0.46 & 0.01 & 0.39 \\
4 & HPMS2-21 & 0.84 & 6 & 0.29 & 0.08 & 0.27 \\
5 & GPM310 & 0.55 & 8 & 0.66 & 0.14 & 0.63 \\
6 & GPMS29 & 0.42 & 6 & 0.67 & 0.18 & 0.60 \\
7 & HPMS1-214 & 0.82 & 6 & 0.32 & 0.09 & 0.31 \\
8 & EPMS342 & 0.67 & 9 & 0.53 & 0.24 & 0.50 \\
9 & GPMS197 & 0.21 & 11 & 0.86 & 0.32 & 0.84 \\
10 & EPMS426 & 0.56 & 7 & 0.58 & 0.17 & 0.52 \\
11 & EPMS1-111 & 0.71 & 11 & 0.49 & 0.36 & 0.47 \\
12 & GPMS161 & 0.33 & 12 & 0.83 & 0.45 & 0.81 \\
13 & HPMS1-5 & 0.41 & 9 & 0.74 & 0.20 & 0.70 \\
& Total & & 111 & & & 0.59 \\
& Average & 0.52 & 8.54 & 0.62 & 0.20 & $0.27-0.87$ \\
\hline
\end{tabular}

susceptible (S), with disease incidence in the ranges of $21-30 \%$ and $31-50 \%$, respectively. High susceptibility, with $>50 \%$ wilt disease incidence, was exhibited only in one germplasm.

\subsection{Amplification and polymorphism of SSR markers}

Twenty SSR markers were tested, of which 15 primers gave clear and reproducible bands and 13 were polymorphic. There were no null alleles across the tested loci. A total of 111 clear and scorable bands were amplified by the polymorphic primers for the tested 75 pepper accessions having SSR fragment sizes ranging from 79-363 base pairs. The number of scorable alleles produced per primer ranged from 5 to 13 , with an average of 8.54 (Table 3). Primer GPMS386 generated the highest number of alleles (13) followed by GPMS161 with 12 alleles. Primer HPMS2-24 generated the smallest number of alleles, i.e., five. The major allele frequency of SSR markers ranged from 0.23 to 0.84 and the mean major allele frequency was 0.52 . HPMS2-21 showed the highest major allele frequency of 0.84 , while GPMS386 showed the lowest major allele frequency of 0.23 .

The polymorphism information content (PIC) value ranged from 0.27 to 0.87 , with an average of 0.59 . The highest PIC value (0.87) was detected by EPMS386 followed by GPMS197 (0.84). Markers GPMS161, GPMS169 and HPMS1-5 exhibited PIC value of 0.81, 0.78 and 0.70 , respectively, whereas the lowest PIC value $(0.27)$ was detected by marker HPMS2-21, followed by marker HPMS1-214 with PIC value of 0.31 .

\subsection{Gene diversity among hot pepper accessions}

The gene diversity indices were highly variable across SSR loci and ranged from 0.29 to 0.88 , with an average value of 0.62 . Gene diversity was found to be highest (0.88) with primer GPMS386. The lowest gene diversity value $(0.29)$ was detected for marker HPMS221, followed by marker HPMS1-214 with genetic diversity of 0.32 (Table 3). Seven SSR primers showed higher gene diversity than the average value (0.62). Observed heterozygosity was also highly variable between loci and ranged from 0.01 to 0.45 . GPMS161 showed the highest heterozygosity (0.45), followed by EPMS1-111 (0.36); the average heterozygosity was 0.20 .

\subsection{Genetic distance and clustering analysis}

The genetic distances between all combinations of any two accessions were investigated and the dissimilarity values ranged from 0.042 to 1.00 . The genetic distances among the 75 accessions ranged from 0.12 to 1.00 . The highest genetic distance was observed between samples no. 11 (from Amhara, Gojam) and 33 (from Amhara, Gonder). The lowest (0.12) genetic distance was found between samples no. 65 (from Benishangul-Gumuz) and 67 (from Amhara, Gojam). All accessions showed an average genetic similarity of 0.59 , which may indicate that these accessions share an average of $59 \%$ of their band fragments detected by the SSR markers used in this study. Based on the dissimilarity matrix, the 75 pepper accessions analysed using SSR markers were grouped into three major clusters that 


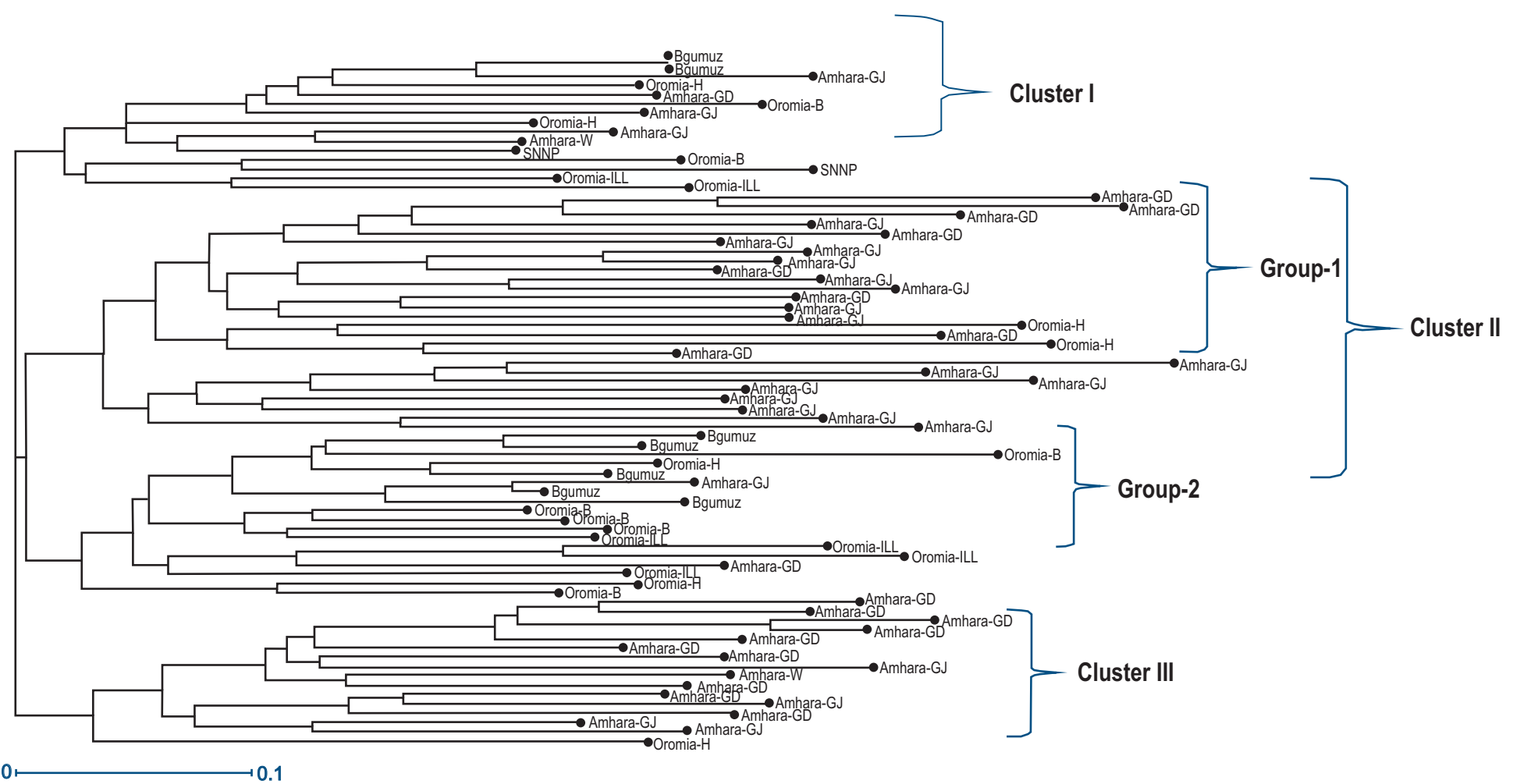

Fig. 3. UPGMA based dendrogram for 75 accessions of Capsicum annuum using 13 SSR primers based on the matrix of genetic similarity estimates using DARwin version 6 software

comprised 16, 44 and 15 accessions (Fig 3). The first cluster grouped almost all accessions (except one) from the Amhara region, i.e., 10 (63\%) from Gonder and 4 (25\%) from Gojam. The second cluster (cluster II) was further divided into two groups. In group one, among the 18 accessions, $11(61 \%)$ were from the Oromia region, whereas in group two, out of the 26 accessions, $16(61 \%)$ were from Amhara-Gojam and $8(31 \%)$ from Amhara-Gonder, while the remaining $2(8 \%)$ from the Oromia region. The third cluster comprised 15 accessions from: Oromia (6), Amhara (5), SNNP (2) and Benishangul Gumuz (2).

\subsection{Population genetic diversity}

Genetic diversity was also estimated for populations by grouping accessions based on the origin of the collection. Within populations, the PIC value ranged from 0.31 (SNNP and Benishangul-Gumuz) to 0.77 (Amhara, Gojam) with a mean of 0.45 . Similarly, gene diversity ranged from 0.36 to 0.80 , with a mean value of 0.50 , in the same order of regions as indicated above. The number of effective allele values ranged from 1.7 to 3.6 with a mean value of 2.39 . Heterozygosity was varying from 0.10-0.22 (Table 4).

Table 4. Characteristics of tested hot pepper (Capsicum annuum) accessions within regions/populations

\begin{tabular}{lcccccc}
\hline Region/population & $\begin{array}{c}\text { Allele } \\
\text { Freq. }\end{array}$ & Allele no. & $\begin{array}{c}\text { Effective no. } \\
\text { of alleles }\end{array}$ & $\begin{array}{c}\text { Gene } \\
\text { diversity }\end{array}$ & Heterozygosity & PIC \\
\hline Amhara Gojam & 0.50 & 6.31 & 3.6 & 0.80 & 0.22 & 0.77 \\
Amhara Gonder & 0.53 & 5.31 & 3.0 & 0.60 & 0.22 & 0.56 \\
Amhara Wello & 0.67 & 2.23 & 1.7 & 0.43 & 0.17 & 0.35 \\
Oromia Bale & 0.64 & 3.23 & 2.3 & 0.48 & 0.22 & 0.43 \\
Oromia Illubabor & 0.65 & 3.08 & 2.4 & 0.45 & 0.17 & 0.40 \\
Oromia Harerge & 0.63 & 3.46 & 2.3 & 0.50 & 0.10 & 0.46 \\
SNNP & 0.72 & 2.15 & 1.9 & 0.36 & 0.10 & 0.31 \\
Benishangul Gumuz & 0.72 & 2.23 & 1.9 & 0.36 & 0.11 & 0.31 \\
\hline Mean & 0.63 & 3.5 & 2.39 & 0.50 & 0.16 & 0.45 \\
\hline
\end{tabular}


Table 5. Pairwise population matrix of Nei’s genetic distances

\begin{tabular}{|c|c|c|c|c|c|c|c|c|}
\hline Amhara-GJ & Amhara-GN & Amhara-W & SNNP & Oromia-B & Oromia-ILL & Oromia-H & Bgumuz & \\
\hline 0.00 & & & & & & & & Amhara-GJ \\
\hline 0.15 & 0.00 & & & & & & & Amhara-GN \\
\hline 0.35 & 0.39 & 0.00 & & & & & & Amhara-W \\
\hline 0.38 & 0.44 & 0.20 & 0.00 & & & & & SNNP \\
\hline 0.18 & 0.24 & 0.37 & 0.45 & 0.00 & & & & Oromia-B \\
\hline 0.23 & 0.28 & 0.46 & 0.45 & 0.17 & 0.00 & & & Oromia-ILL \\
\hline 0.22 & 0.25 & 0.46 & 0.48 & 0.25 & 0.34 & 0.00 & & Oromia-H \\
\hline 0.24 & 0.30 & 0.46 & 0.43 & 0.16 & 0.20 & 0.19 & 0.00 & Bgumuz \\
\hline
\end{tabular}

Explanations: GJ - Gojam, GN - Gonder, W - Wello, SNNP - Southern Nations, Nationalities and Peoples, B - Bale, ILL - Illubabor, H - Harerge, Bguumuz - Benishangul-Gumuz

Table 6. Analysis of molecular variance among the 8 populations of Capsicum annuum without grouping

\begin{tabular}{lrrrrrrr}
\hline Source of variation & df & $\begin{array}{r}\text { Sum of } \\
\text { squares }\end{array}$ & $\begin{array}{c}\text { Mean } \\
\text { square }\end{array}$ & Est. Var. & $\begin{array}{r}\% \text { of } \\
\text { variance }\end{array}$ & F $_{\text {ST }}$ & P-value \\
\hline Among Populations & 7 & 79.063 & 11.295 & 0.276 & 7 & 0.214 & 0.05 \\
Among Individuals & 67 & 442.330 & 6.602 & 2.654 & 63 & & \\
Within Individuals & 75 & 97.000 & 1.293 & 1.293 & 31 & & \\
Total & 149 & 618.393 & & 4.224 & 100 & & \\
\hline
\end{tabular}

\subsection{Population genetic distance and clustering analysis}

The genetic distances among the populations (accessions collected from different regions/provinces) ranged from 0.15 to 0.48 . The highest genetic distance $(0.48)$ was found between the populations from SNNP and Oromia (Harerge). Whereas the lowest genetic distance $(0.15)$ was revealed between accessions from Amhara (Gojam) and Amhara (Gonder). The highest genetic distance ranging from 0.38 to 0.48 was observed between SNNP and the other populations, except for Amhara
(Wello) where it was only 0.20 (Table 5). Clustering of the eight populations based on UPGMA resulted in two main clusters. The first cluster (I) grouped populations from Amhara (Wello) and SNNP, while the second cluster (II) contained the remaining six populations. The second cluster was further divided into two subclusters. Accessions from Amhara (Gojam and Gonder) and Oromia (Harerge) occurred in the first subgroup, while accessions from Oromia (Bale and Illubabor) and Benishangul-Gumuz in the second subgroup (Fig. 4).

Analysis of molecular variance (AMOVA) indicated a total of $63 \%$ variation among individuals. Similarly,

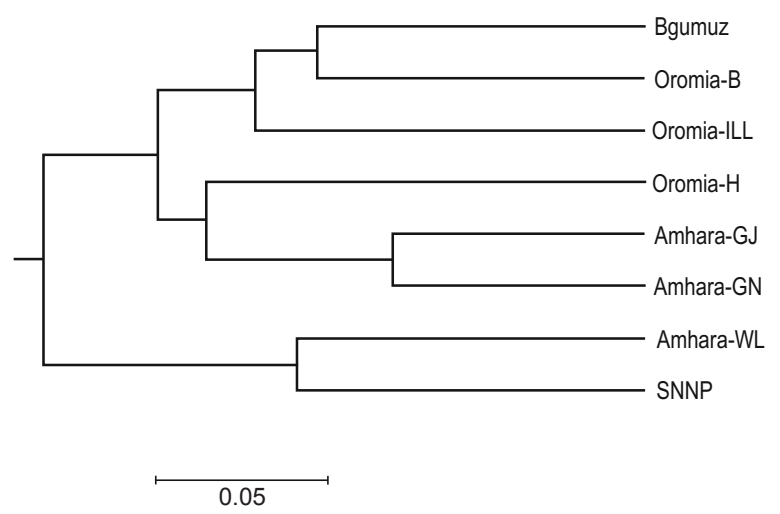

Fig. 4. UPGMA based dendrogram for 8 populations of Capsicum annuum using 13 SSR primers

Explanations: Bgumuz - Benishanngul-Gumuz, B - Bale, ILL - Illibabur, H - Harerge, GJ - Gojam, GN - Gonder, WL - Wello 
variations observed within individuals and populations were $31 \%$ and $7 \%$, respectively. Variation with 0.214 fixation index $\left(\mathrm{F}_{\mathrm{ST}}\right)$ indicates about $21 \%$ genetic differentiation among populations independent of the marker used $(\mathrm{P}<0.05)$ (Table 6).

\section{Discussion}

The hot pepper accessions used in this study exhibited a range of reactions to the infection with wilt disease-causing pathogens, as measured based on per cent disease incidence (total number of dead to living plants) of each genotype under natural field infection. Based on incidence per cent from the total of 75 hot pepper genotypes screened, 32 (43\%) of the accessions were highly to moderately susceptible to wilt disease-, whereas $43(57 \%)$ of the tested accessions were resistant and moderately resistant, with a disease incidence of 1-20\%. No accession exhibited complete resistance against wilt disease. The present study agrees with the report of Mamta et al. (2012), which indicated high disease incidence variation within the range of 0 to $78.7 \%$ from thirty varieties screened. The selected resistant accessions could be used as a source of resistance against wilt disease in the breeding program in Ethiopia.

Knowledge of diversity in plant genetic resources provides an opportunity for plant breeders to develop new and improved cultivars with desirable characteristics. Besides, such information can be used to design effective germplasm conservation and for launching germplasm collection missions, as well as to predict the risk of genetic erosion in a given area. The pattern of genetic variability can be studied by morphological, biochemical and molecular markers. Among molecular markers, simple sequence repeats (SSR) are favored as molecular-genetic markers due to their high polymorphism index (Mun et al. 2006). In this study, the high level of polymorphism detected among the 75-germplasm assay demonstrated the efficiency of SSR markers for determining the level of variation among hot pepper germplasms. SSR markers were used successfully for diversity assessment in capsicum species in previous studies (González-Pérez et al. 2014; Zhang et al. 2016; Guzmán et al. 2019). The 13 microsatellite markers used in this study generated 111 alleles, and a significant number of distinct alleles was also observed. According to Jain et al. (2004), rare alleles are highly informative for genotyping of germplasm and can serve as an indicator of the presence of unique genetic variants or differentiated populations. Botstein et al. (1980) reported that PIC values above 0.5 are consistent with the usefulness of the marker. Based on PIC values, the level of polymorphism of the 13 microsatellites was very high, ranging from 0.27 to 0.87 with an average of 0.59 , indicating the presence of an immense genetic diversity among the germplasms. Most of the markers $(69 \%)$ were considered highly informative. Four SSR markers $(31 \%)$ were moderately informative. The PIC values observed in this study are close to values reported in the literature for capsicum species (Lee et al. 2016; Zhang et al. 2016). Therefore, these microsatellite markers could accordingly be used to discover duplicated entries in ex-situ germplasm collections of Capsicum.

Regardless of region, the gene diversity indices were highly variable across SSR loci and ranged from 0.29 to 0.88 with a mean genetic diversity value of 0.62 . Observed heterozygosity was also highly variable between loci (0.01-0.45) with an average of 0.20 , indicating that the accessions were not fixed to homozygosity. The level of diversity observed in this study is comparable to the findings of Zhang et al. (2016) for collections from China and Nicolai et al. (2013) for germplasm collections maintained at the French National Institute for Agricultural Research (INRA). Using quantitative and qualitative traits, the presence of high genetic variation in Ethiopian pepper has been reported by works by Aklilu et al. (2016) and Belay et al. (2019). Solomon et al. (2019) also reported similar results using phenotypic and molecular markers. In our study, within the population, the highest genetic diversity value of 0.88 was recorded in the Amhara region, whereas in the Oromia region, genetic diversity ranged from 0.45 to 0.50 . The lowest genetic diversity of 0.36 was found in SNNP and Benishangul-Gumuz. The highest and lowest genetic diversity from Amhara and SNNP, respectively, could be due to variation in the size of tested accessions. In general, the greater the genetic diversity of germplasm, the greater is the chance of success in breeding desirable strains. The observed high genetic diversity for the population from the Amhara and Oromia regions may indicate these areas as the primary sites for designing conservation strategies for hot pepper in Ethiopia. In these regions, red pepper is a major spice and vegetable crop produced by most smallholder producers (Wubalem 2019). The genetic distances among the populations ranged from 0.15 to 0.48 . The highest genetic distance (0.48) was exhibited between populations from SNNP and Oromia (Harerge). A high genetic distance between the two geographically distant regions suggests the existence of excessive genetic variation between them. In turn, the lowest genetic distance $(0.15)$ was found between accessions from Amhara (Gojam) and Amhara (Gonder). UPGMA clustering of accessions based on the genetic distance showed that geographically closely related hot pepper accessions have been clustered together. Similar observations were reported using ISSR markers (Alayachew et al. 2016). 


\section{Conclusion and recommendations}

The molecular results provided evidence for the presence of genetic diversity among the accessions. The information generated from this study provides baseline information to target a collection mission for conservation purposes and exploit the genetic resources for the crop improvement, as well as resistance sources to be used for the breeding program in Ethiopia. It is recommended to test further large and proportional sample sizes across regions to gain knowledge on the overall structure and diversity of hot pepper germplasm in the country.
Acknowledgements. The authors thank Dr Marion S. Roder, Leibniz Institute of Plant Genetics and Crop Plant Research (IPK) Gatersleben, Germany and Dr Ermias Habte, ILRI, Addis Ababa, Ethiopia for kindly providing the SSR markers used in the present study.

\section{Author Contributions}

Research concept and design: D. B. Woubit

Acquisition and/or assembly of data: D. B. Woubit, S. Eleni, S. Fitsum, A. Mekonnen, A. Shimeles

Data analysis and interpretation: D. B. Woubit, S. Eleni

Drafting the article: D. B. Woubit

Critical revision: D. B. Woubit, S. Eleni

Final approval: D. B. Woubit, S. Eleni, S. Fitsum, A. Mekonnen, A. Shimeles

\section{References}

Alayachew S. A., Atnafu D. M. \& Gedeta S. A. 2018. Genetic diversity study of Ethiopian hot pepper Cultivars (Capsicum species) using Inter Simple Sequence Repeat (ISSR) Marker. Int J Agr Res 13(2): 65-73. DOI: 10.3923/ijar.2018.65.73

Aklilu S., Abebie B., Wegary D. \& Tekleword A. 2016. Analysis of morphological diversity among hot pepper (Capsicum annuum L.) collections in the Rift Valley area of Ethiopia. Trop Agr 93(3):152-164.

BARC (Bako Agricultural Research Center). 1999/2000. Crop Protection Research Division Progress Report.

Bayoumi T. Y. \& El-Bramawy M. A. S. 2007. Genetic analyses of some quantitative characters and Fusarium wilt disease resistance in sesame. In African Crop Science Conference Proceedings 8: 2198-2204.

Belay F., Abate B. \&Tsehaye, Y. 2019. Genetic diversity studies for morphological traits of hot pepper (Capsicum annuum L.) genotypes in Central Zone of Tigray Region, Northern Ethiopia. Afr J Agri Res 4(33): 1674-1684. https://doi.org/10.5897/AJAR2019.14256

Botstein D., White R. L., Skolnick M. \& Davis R. W. 1980. Construction of a genetic linkage map in man using restriction fragment length polymorphism. Am J Hum Genet 2: 314-331.

Byoung-Cheorl K., Inhwa Y \& Molly M. J. 2005. Genetics of Plant Virus Resistance. Ann Revf Phytopathol 43: 581-621.

Central Statistics Agency (CSA). 2018. Agricultural sample survey 2019/20. Vol. I. Report on Area and Production of Major Crops. Central Statistics Agency, Federal Democratic Republic Ethiopia, Statistical Bulletin. Addis Ababa, pp: 11-13.

Doyle J. J. \& Doyle J. L. 1987. A rapid DNA isolation procedure for small quantities of fresh leaf tissue. Phytochemical Bulletin 19: 11-15.

Dale J. W. \& Schanz M. 2002. From Genes to Genomes, Concept and Applications of DNA Technology. 360 pp. John Wiley and Sons, Limited. England.
Duveiller E., Singh R. P. \& Nicol J. M. 2007. The challenges of maintaining wheat productivity: pests, diseases, and potential epidemics. Euphytica 157: 417-430.

EEPA (Ethiopian Export Promotion Agency). 2014. Export performance of Agricultural products. Addis Ababa, Ethiopia.

FAO. 2013. FAOSTAT. Food and Agriculture Organization of the United Nations. Website http://faostat.fao.org/ default.aspx.

FAOSTAT. 2016. Crop production in Africa. Retrieved 2018, August 18. Countries-select all; regions-Africa+(Total); elements-area and production quantity; items-red pepper; Years-2010-2016. http://www.fao.org/faostat/ en/\#data/QC/[Online]

Galanihe L. D., Priyantha M. G. D. L., Yapa D. R., Bandara H. M. S. \& RANASINGHE J. 2004. Insect pest and disease incidences of exotic hybrids chilli pepper varieties grown in the low country dry zone of Sri Lanka. Annals of Sri Lanka 6: 99-106.

Girma H., Digafe T., Edossa E., Belay Y. \& Weyessa G. 2008. Spices research achievements. Ethiopian Institute of Agricultural Research Annual Report, pp 12-22.

González-Pérez S., Garcés-Claver A., Mallor C., SÁenz de Miera L. E., Fayos O., Pomar F., Merino F. \& Silvar C. 2014. New Insights into Capsicum spp. relatedness and the diversification process of Capsicum annuum in Spain. PLoS ONE 9(12): 1-23.

Guzmán, F. A., Moore S., Vicente M. C. \& Jahn M. M. 2019. Microsatellites to enhance characterization, conservation and breeding value of Capsicum germplasm. Genet Resour Crop Ev 67: 569-585.

JAIN S., JAIN R. K. \& McCouch S. 2004. Genetic analysis of Indian aromatic and quality rice (Oryza sativa L.) germplasm using panels of fluorescently labelled microsatellite markers. Theor Appl Genet 109(5): 965-977. DOI: 10.1007/s00122-004-1700-2

Korobkon A., Tegegn T. \& Dilbo C. 1986. Chemical control of bacterial leaf spot of hot pepper (Capsicum annuum L.) 
Caused by Xanthomonas campestris pv. vesicatoria. Scientific phyto pathological Laboratory (SPL) progress Report for the period 1985/86, pp.192-199.

Lee H. Y., Ro N. Y., Jeong H. J., Kwon J. K., Jo J., Ha Y., Jung A., Han J. W. Venkatesh J. \& Kang B. C. 2016. Genetic diversity and population structure analysis to construct a core collection from large Capsicum germplasm. BMC Genetics 17: 142. DOI 10.1186/ s12863-016-0452-8

Liu K. \& Muse S. V. 2005. Power Marker: an integrated analysis environment for genetic Marker analysis. Bioinfo. 21: 2128-2129. http://dx.doi.org/10.1093/ bioinformatics/bti282

Mamta J., Rashmi S., Anil K. S. \& Anil P. 2012. Screening of Resistant Varieties and Antagonistic Fusarium oxysporum for Biocontrol of Fusarium Wilt of Chilli. J. Plant Pathol. \& Micr. 3: 134. DOI: 10.4172/21577471.1000134

Mun J. H., Kim D. J., Choi H. K., Gish J., Debell, F. \& Mudge J. 2006. Distribution of microsatellites in the genome of Medicago truncatula: a resource of genetic markers that integrate genetic and physical maps. Genetics 172(4): 25412555. DOI: 10.1534/genetics.105.054791

Nicolai M., Cantet M., Lefebvre V., Sage-Palloix A. M. \& Palloix A. 2013. Genotyping a large collection of pepper (Capsicum spp.) with SSR loci brings new evidence for the wild origin of cultivated C. annuиm and the structuring of genetic diversity by human selection of cultivar types. Genet Resour Crop Ev 60(8): 2375-2390. https://doi.org/10.1007/s10722013-0006-0
Peakall R. \& Smouse P. E. 2012. GenAlEx 6.5: genetic analysis in Excel. Population genetic software for teaching and research-an update. Bioinformatics 28: 2537-2589. DOI: 10.1093/bioinformatics/bts460

Perrier X. \& Jacquemoud-Collet J. P. 2006. DARwin Software. Available from: http://darwin.cirad.fr/darwin

Shimeles A., Berhanu B. \& Bekele K. 2007. Survey report on current pepper production constraints in major pepper growing areas of Ethiopia. EIAR, 2007, Addis Abeba, Ethiopia.

Shimeles A., Getachew A., Bekele A. \& Tesfaye A. 2018. Screening for Resistance Sources in Local and Exotic Hot Pepper Genotypes to Fusarium Wilt (Fusarium oxysporium) and Associated Quality Traits in Ethiopia. Adv Crop Sci 6(3): 367.

Solomon A. M., Han K., Lee J. H., Jang S. \& Kang B. C. 2019. Genetic diversity and population structure of Ethiopian Capsicum germplasms. PLoS ONE 14(5): 1-20. https://doi.org/10.1371/journal.pone.0216886

Wubalem G. 2019. A seminar review on red pepper (Capsicum) production and marketing in Ethiopia. Cogent Food \& Agriculture 5(1): 1-14. https://doi.org/10.10 $80 / 23311932.2019 .1647593$

Zhang X. M., Zhang Z. H., Gu X. Z., Mao S. L., Li X.X., Chadoeuf J., Palloix A., Wang L. H. \& Zhang B. X. 2016. Genetic diversity of pepper (Capsicum spp.) germplasm resources in China reflects selection for cultivar types and spatial distribution. J Integr Agric 15: 1991-2001. https://doi.org/10.1016/S20953119(16)61364-3 